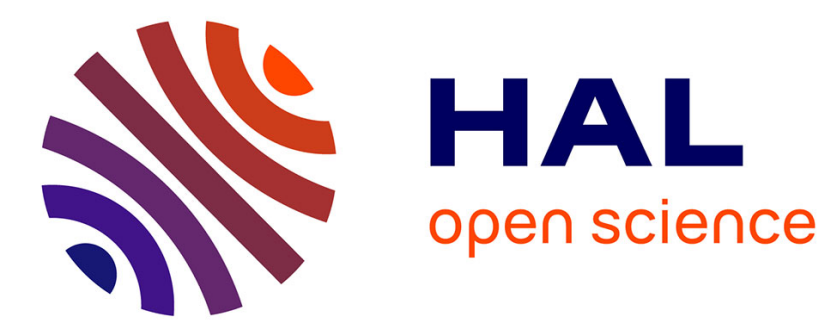

\title{
Influence of the microstructure and laser shock processing (LSP) on the corrosion behaviour of the AA2050-T8 aluminium alloy
}

Hassan Amar, Vincent Vignal, Mourad Haj Krawiec, Courty C. Josse, Patrice Peyre, S. N. da Silva, Luis Dick

\section{To cite this version:}

Hassan Amar, Vincent Vignal, Mourad Haj Krawiec, Courty C. Josse, Patrice Peyre, et al.. Influence of the microstructure and laser shock processing (LSP) on the corrosion behaviour of the AA2050T8 aluminium alloy. Corrosion Science, 2011, 53 (10), pp.3215-3221. 10.1016/j.corsci.2011.05.066 . hal-02413160

\section{HAL Id: hal-02413160 \\ https://hal.science/hal-02413160}

Submitted on 16 Dec 2019

HAL is a multi-disciplinary open access archive for the deposit and dissemination of scientific research documents, whether they are published or not. The documents may come from teaching and research institutions in France or abroad, or from public or private research centers.
L'archive ouverte pluridisciplinaire HAL, est destinée au dépôt et à la diffusion de documents scientifiques de niveau recherche, publiés ou non, émanant des établissements d'enseignement et de recherche français ou étrangers, des laboratoires publics ou privés. 


\title{
Influence of the microstructure and laser shock processing (LSP) on the corrosion behaviour of the AA2050-T8 aluminium alloy
}

\author{
H. Amar ${ }^{a}$, V. Vignal ${ }^{a, *}$, H. Krawiec ${ }^{b}$, C. Josse ${ }^{a}$, P. Peyre ${ }^{c}$, S.N. da Silva ${ }^{\text {d }}$, L.F. Dick ${ }^{d}$ \\ a ICB, UMR 5209, CNRS-Université de Bourgogne, BP 47870, 21078 Dijon, France \\ ${ }^{\mathrm{b}}$ AGH, University of Science and Technology, ul. Reymonta 23, 30-059 Krakow, Poland \\ ' PIMM, UMR 8006, CNRS-Arts et Métiers Paritech, 151 Bd de l'Hôpital, 75013 Paris, France \\ ${ }^{\mathrm{d}}$ Department of Metallurgy, Federal University of Rio Grande do Sul (UFRGS), Av. Bento Gonçalves, 9500 Bl. 4, Prédio 75, Porto Alegre, RS 91501-970, Brazil
}

Keywords:

A. Aluminium alloy

B. Polarization

C. Intergranular corrosion

C. Pitting corrosion

C. Effects of strain

\begin{abstract}
A B S T R A C T
The corrosion behaviour of AA2050-T8 was studied after polishing and after laser shock processing (LSP) treatment using the electrochemical microcell technique and the SVET. After polishing, pitting at constituent particles and intergranular corrosion were observed. By contrast, no intergranular corrosion developed after LSP. Microcell measurements revealed that LSP increases the pitting potential. SVET measurements revealed that local anodic currents are systematically lower on LSP-treated surfaces than on polished ones. The current density on the LSP-treated surface remains constant around $50 \mu \mathrm{A} \mathrm{cm}^{-2} \mathrm{up}$ to $123 \mathrm{~min}$ after immersion, while on the polished surface it reaches $200 \mu \mathrm{A} \mathrm{cm}{ }^{-2}$.
\end{abstract}

\section{Introduction}

Aluminium alloys are a very important category of materials because of their outstanding mechanical properties and wide range of industrial applications. It is well known [1-3] that aluminium alloys are prone to microstructural corrosion (pitting corrosion, intergranular corrosion, etc.). Microstructural corrosion is caused by the presence of intermetallic particles, which may be either anodic or cathodic with respect to the matrix [1-4]. Micro-electrochemical techniques have been widely employed to obtain information about the role of these particles in localised corrosion of aluminium alloys. Park et al. [5] used a pH microelectrode and demonstrated that alkalisation occurred around a synthetic $\mathrm{Al}_{3} \mathrm{Fe}$ $\left(200 \times 200 \mu^{2}\right)$ electrode coupled to a 6061 alloy sample in $\mathrm{NaCl}$ $0.6 \mathrm{M}$ at $\mathrm{pH}$ 6.3. The local dissolution of various aluminium alloys has been probed in situ [6] in chloride solutions by using atomic force microscopy (AFM) and scanning electrochemical microscopy (SECM). Preferential dissolution in the boundary region between some intermetallic particles (IMPs) and the alloy matrix, and trench formation around large IMPs during free immersion and under electrochemical anodic polarisation were observed. The use of microcapillary cell techniques [7-10] enables the measurement of local breakdown potentials for areas in aluminium alloys containing

\footnotetext{
* Corresponding author. Tel.: +33 (0) 380396160; fax: +33 (0) 380396132.

E-mail addresses: vvignal@u-bourgogne.fr, vincent.vignal@u-bourgogne.fr (V. Vignal).
}

one or a few intermetallics [11-13]. A mathematical model for simulating the local electrochemical response of a passive aluminium surface with an active pit has been developed [14]. This model was applied to a real capillary geometry used in electrochemical microcell experiments. It was found that for $r_{\text {cap }} / r_{\text {pit }}<100$, where $r_{\text {cap }}$ and $r_{\text {pit }}$ are the capillary tip and pit radii respectively, the insulating capillary wall affects the species concentrations and the electrolyte potential. Moreover, for $r_{\text {cap }} / r_{\text {pit }}<20$, the shape of the capillary, which might not be cylindrical, should be taken into account.

Main applications of LSP treatment are directed to aerospace and automotive industries [15]. LSP treatment consists in irradiating material surfaces with nanosecond laser pulses that generate plasma-driven shock waves, which in turn lead to a certain amount of local plastic deformation. Thermal effects are avoided by covering the surface with an absorptive overlay. Deep (i.e. greater than $0.5 \mathrm{~mm}$ ) and high-amplitude compressive residual stress fields, combined with relatively low work hardening rates (less than $20 \%$ ) and limited roughening, are usually the main characteristics of surfaces having undergone LSP treatment.

The beneficial effects of LSP on static, cyclic and fretting fatigue performance of aluminum alloys, steels and nickel-based alloys have been demonstrated [ 15 and Ref. therein]. LSP treatment is also expected to improve the corrosion behaviour of aluminium alloys. Previous works at the macro-scale have provided evidence of an anodic shift of the pitting potential of 2024-T351 aluminium alloy treated by LSP [16]. In this paper, the influence of the specimen microstructure and LSP on the resistance to localised corrosion of 
AA2050-T8 aluminium alloy is investigated in chloride media at the microscale using microcapillaries, the SVET and FE-SEM/EDS.

\section{Experimental}

\subsection{Specimens and surface preparation}

Experiments were performed on the 2050-T8 aluminium alloy (Cu: 3.73 wt.\%; Li: 0.9 wt.\%; Mg: 0.3 wt.\%; Mn: 0.37 wt.\%; Zr: 0.009 wt.\% and Fe: 0.05 wt.\%). Specimens were ground with silicon carbide ( $\mathrm{SiC}$ ) papers down to 4000 grit and polished with diamond pastes ( 9,3 and $1 \mu \mathrm{m})$.

Prior to LSP, specimens were covered with an $80 \mu \mathrm{m}$-thick metal adhesive coating so as to prevent any thermal rise during LSP and hence any microstructural changes. As shown in Fig. 1(a), the specimen surface was partially treated by LSP. Experiments were carried out with a frequency-doubled $(0.532 \mu \mathrm{m}) \mathrm{Nd}$ :YAG laser capable of delivering up to $1.5 \mathrm{~J}$ in pulses of $9 \mathrm{~ns}$ duration at a $10 \mathrm{~Hz}$ repetition rate. $1.8 \mathrm{~mm}$ impact diameters were used to treat $1.5 \mathrm{~cm}$ circular areas. The intensity value was $3.5 \mathrm{GW} \mathrm{cm}^{-2}$.

\subsection{Global and local electrochemical measurements}

Global polarisation curves were determined on the polished and LSP-treated surfaces using a classical three-electrode cell. All potentials were measured vs. $\mathrm{Ag} / \mathrm{AgCl}$ (in saturated $\mathrm{KCl}$ solution) and the counter electrode was a platinum disk ( $1 \mathrm{~cm}$ diameter). An AutoLab PGZ128 electrochemical interface was used in these experiments. On the other hand, local polarisation curves were determined using the electrochemical microcell technique [17-19]. The microcell was mounted on a microscope for precise positioning of the capillary on its surface. The capillary tip was sealed to the specimen surface with a layer of silicon rubber. The wetted area on the specimen could be calculated accurately using a specific image analysis procedure. All potentials were measured vs. $\mathrm{Ag} / \mathrm{AgCl}$ (saturated $\mathrm{KCl}$ solution) and the counter electrode was a platinum wire. Local polarisation curves were determined using capillary diameters of
400 and $25 \mu \mathrm{m}$. A high-resolution potentiostat (Jaissle IMP83 PCT-BC) was used in these experiments with a current detection limit of approximately $20 \mathrm{fA}$. At the micro- and macro-scale, polarisation curves were plotted at $16.6 \mathrm{mV} \mathrm{s}^{-1}$ in $0.1 \mathrm{M} \mathrm{NaCl}$ (aerated solution) at $25 \pm 1^{\circ} \mathrm{C}$. The potential range was from $-1500 \mathrm{mV} /$ SCE up to the pitting potential. No prior polarisation was applied to the system.

Local current measurements were performed at OCP in $5 \mathrm{mM}$ $\mathrm{NaCl}+50 \mathrm{mM} \mathrm{Na}_{2} \mathrm{SO}_{4}$ (conductivity: $0.783 \mathrm{mS}$ ) using an Applicable Electronics SVET. Pt-Ir microelectrodes (MicroProbe Inc.) were black platinised and the sphere diameter after deposition was about $20 \mu \mathrm{m}$. The vibration amplitude was $20 \mu \mathrm{m}$ and the vibration frequency was 600 and $200 \mathrm{~Hz}$ in the direction parallel and normal to the surface, respectively. The Y-component of the current was measured The ASET Software (Science Wares Inc.) converted the potential drop measured by the microelectrode with Ohm's law into a current density value after amplification. The distance between the SVET tip and the sample surface was fixed to $100 \mu \mathrm{m}$. SVET measurements were carried out along a line $(600 \mu \mathrm{m}$ in length) across the interface between the LSP-treated surface and the polished surface at different times of immersion. The distance between two measurement points was $2 \mu \mathrm{m}$. The displacement of the microelectrode was performed using a motorised and computer-controlled XYZ micromanipulator.

\subsection{Surface observations and stress measurements at the microscale}

A field emission scanning electron microscope (JEOL 6400F) with an integrated electron dispersion spectrometer (FE-SEM/ EDS) was used to determine the morphology and chemical composition of constituent particles. AFM images were obtained in air from a Q-Scope 350 microscope (Quesant Instruments Corporation) in the tapping mode (vibration frequency of $174 \mathrm{kHz}$ ). Surface roughness values $\left(R_{\mathrm{a}}\right)$ were calculated from AFM images $\left(40 \times 40 \mu \mathrm{m}^{2}\right)$.

Residual stresses ( $\sigma_{11}$ and $\sigma_{22}$ along the $X_{1}$ - and $X_{2}$-axis, respectively) were determined on the polished and LSP-treated surfaces
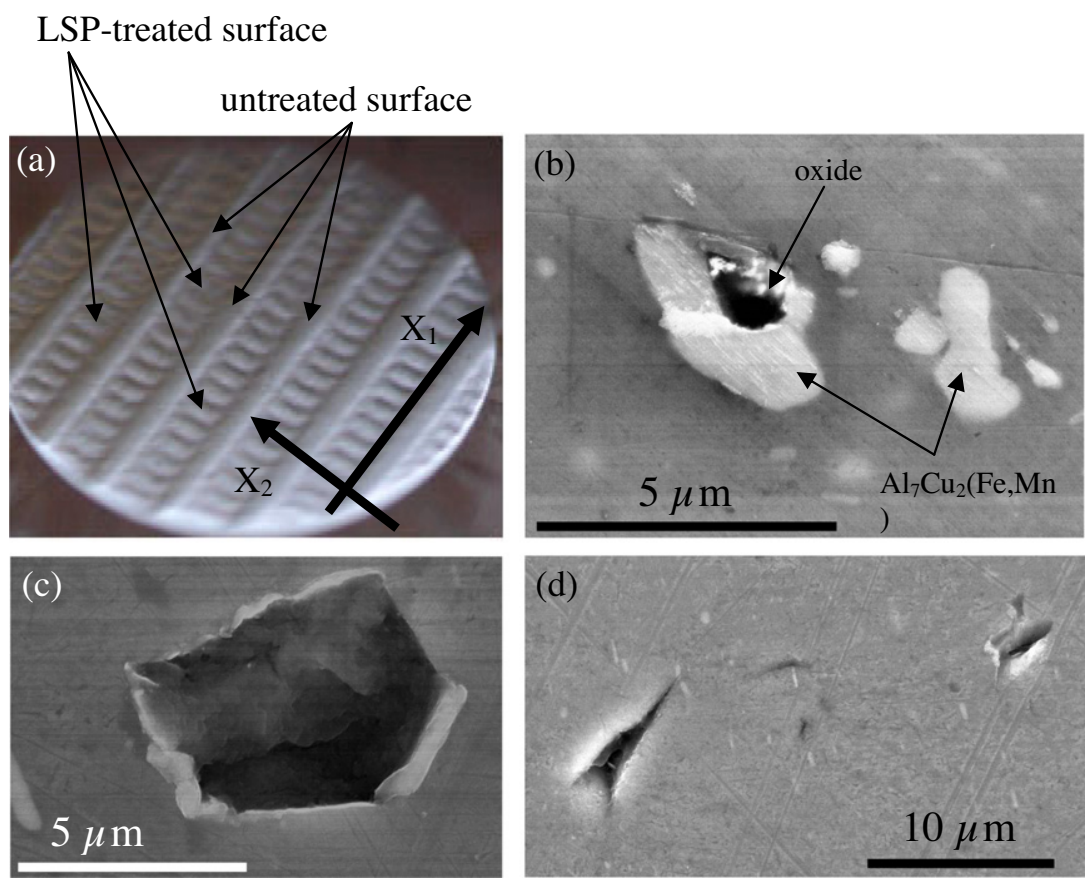

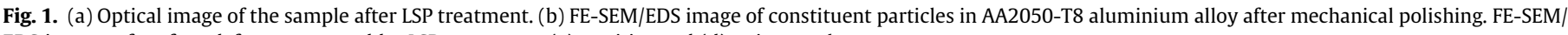
EDS images of surface defects generated by LSP treatment: (c), cavities and (d), microcracks. 
using an X-ray $\theta / \theta$-type goniometer (D8 Discover with the General Area 2D Detector Diffraction System from Bruker AXS). The X-ray beam was focused using an aperture (diameter of $50 \mu \mathrm{m}$ ). Experiments were carried out on $\left\{\begin{array}{lll}3 & 1 & 1\end{array}\right\}$ planes using the $\sin ^{2} \psi$ method [20]. The X-ray elastic constant was $1 / 2 \mathrm{~S}_{2}=1.9 \times 10^{-5} \mathrm{MPa}^{-1}$.

\section{Results and discussion}

The influence of LSP on the microstructure of AA2050-T8 has been investigated in a previous work [21]. FE-SEM/EDS observations revealed the presence of $\mathrm{Al}_{7} \mathrm{Cu}_{2}(\mathrm{Fe}, \mathrm{Mn})$ constituent particles, as shown in Fig. 1(b). Their size was in the range of 1-10 $\mu \mathrm{m}$ and their chemical composition was $73.97 \pm 8.8$ at\% $\mathrm{Al}, 17.6 \pm 8$ at\% $\mathrm{Cu}$, $5 \pm 2.6$ at\% Fe and $3.3 \pm 2.4$ at\% Mn. Oxide particles have also been detected. They contained oxygen (22.7 \pm 2 at\%), aluminium (67.6 \pm 0.4 at\%), copper ( $2.5 \pm 1$ at $\%$, iron ( $0.6 \pm 0.6$ at $\%$ ), manganese $(1.4 \pm 1.3$ at\%) and silicon $(5.1 \pm 1.2$ at\%). On the other hand, the matrix was composed of aluminium $(97.9 \pm 0.09$ at\%) and copper ( $2 \pm 0.07$ at\%). TEM experiments [22] have revealed that the main hardening phase in AA2050-T8 was $\mathrm{Al}_{2} \mathrm{CuLi}$. It has been shown [21] that LSP treatment has no influence on the size and chemical composition of constituent particles, hardening particles and oxides.

By contrast, LSP affects the residual stress values. Extremely low stress values were registered after mechanical polishing $\left(\sigma_{11}=-30 \pm 30 \mathrm{MPa}\right.$ and $\left.\sigma_{22}=15 \pm 25 \mathrm{MPa}\right)$. After LSP treatment, sites containing the pure matrix were found to be under compres$\operatorname{sion}\left(\sigma_{11}=-165 \pm 40 \mathrm{MPa}\right.$ and $\left.\sigma_{22}=-160 \pm 30 \mathrm{MPa}\right)$.

\subsection{Corrosion behaviour of AA2050-T8 in $0.1 \mathrm{M} \mathrm{NaCl}$ after mechanical polishing}

\subsubsection{Global polarisation curves}

Global polarisation curves in $0.1 \mathrm{M} \mathrm{NaCl}$ reveal the presence of a two-stage breakdown mechanism in AA-2050-T8 aluminium alloy after mechanical polishing (Fig. 2(a)). The first stage occurs for applied potentials greater than $E_{\mathrm{b} 1}=-785 \mathrm{mV}$ vs. $\mathrm{Ag} / \mathrm{AgCl}$. The second stage is observed for potentials greater than $E_{\mathrm{b} 2}=-610 \mathrm{mV}$ vs. $\mathrm{Ag} / \mathrm{AgCl}$. These two stages are associated with a rapid rise in the anodic current density. As previously explained [23,24], they correspond to the dissolution potential of second phase particles.

\subsubsection{Corrosion behaviour above the potential $E_{b 1}$}

To determine the corrosion mechanisms occurring at the first potential $E_{\mathrm{b} 1}$, samples were exposed to the electrolyte at the ОСР value for $25 \mathrm{~min}$. The steady state corrosion potential had a value around $-700 \mathrm{mV}$ vs. $\mathrm{Ag} / \mathrm{AgCl}$ (between $E_{\mathrm{b} 1}$ and $E_{\mathrm{b} 2}$ ). FE-SEM/EDS observations revealed that grain boundaries were not dissolved, but sites containing large constituent particles were preferentially oxidised (Fig. 3 ).

Some sites were slightly oxidised, as shown in Fig. 3(a). An FE-SEM/EDS analysis revealed that the matrix contains the same quantity of copper as prior to immersion (approximately 2 at.\%, as shown in Table 1). A small amount of iron (0.13 at.\%) and manganese ( 0.66 at.\%) was detected in the immediate vicinity of constituent particles (Table 1 ). This suggests that these two elements were dissolved and re-deposited on the surrounding matrix during immersion. Fe and Mn were not detected in the matrix after polishing. Oxygen was preferentially absorbed in constituent particles (18 at.\% in Table 1 ) and in the matrix surrounding these particles (8.5 at.\%). Only 2 at.\% of oxygen was detected in areas of the matrix far from constituent particles. Increased passivity in areas of the matrix adjacent to constituent particles was then observed.

Other sites were strongly oxidised. An FE-SEM/EDS analysis of the oxide layer formed around constituent particles (Fig. 3(b))
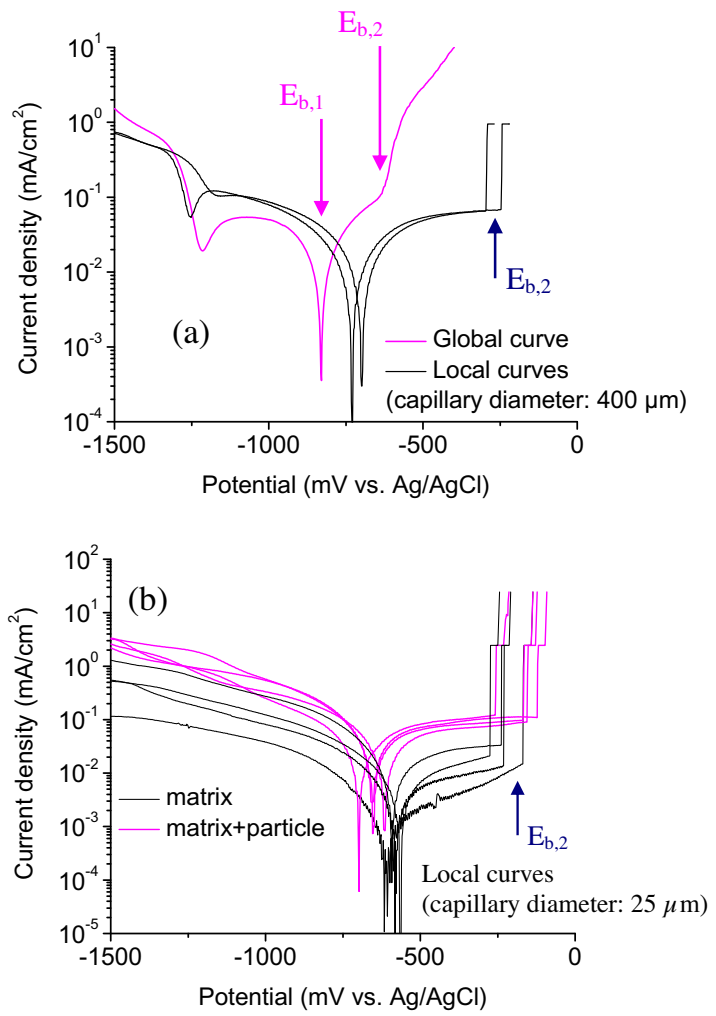

Fig. 2. (a and b) Global and local polarisation curves $(16.6 \mathrm{mV} / \mathrm{s})$ for AA2050-T8 aluminium alloy in $0.1 \mathrm{M} \mathrm{NaCl}$ at $25^{\circ} \mathrm{C}$. Experiments were carried out after mechanical polishing.

revealed the following composition: 48.7 at.\% 0,43 at.\% $\mathrm{Al}$, 5.05 at.\% Cu, 4 at.\% $\mathrm{Mn}, 1.95$ at.\% Fe and 0.2 at.\% Cl. Therefore, aluminium oxide or hydroxide first formed around constituent particles before covering them completely. These surface observations confirm that constituent particles in the 2050-T8 aluminium alloy behave as cathodic sites.

Enrichment in copper of constituent particles (induced by preferential dissolution of $\mathrm{Fe}$ and $\mathrm{Mn}$ ) enhances their cathodic behaviour, and oxygen reduction takes place at their surface. It has been proposed for AA2024-T351 aluminium alloy in $0.1 \mathrm{M} \mathrm{Na}_{2}$ $\mathrm{SO}_{4}+0.001 \mathrm{M} \mathrm{NaCl}$ solution [25] that the galvanic coupling between constituent particles (cathodic sites) and the surrounding matrix (anodic site) can explain the increased passive behaviour of the adjacent matrix zone.

\subsubsection{Corrosion behaviour above the potential $E_{b 2}$}

For potentials at $E_{\mathrm{b} 2}$ and above, both pitting and intergranular corrosion developed, as shown in Fig. 3(c and d). These figures present AFM images of the sample surface after interruption of the polarisation curve at $-250 \mathrm{mV}$ vs. $\mathrm{Ag} / \mathrm{AgCl}$ (i.e. an applied potential greater than $E_{\mathrm{b} 2}$ ). The grain boundaries were attacked and large pits developed within the grains. Two intergranular corrosion mechanisms have been proposed in the literature [26,27], corresponding to the preferential dissolution of the precipitate free zone (PFZ) along grain boundaries or of grain boundary precipitates. In the later case, if the initial grain boundary precipitate is $\beta^{\prime}$ or $\beta\left(\mathrm{Mg}_{2} \mathrm{Al}_{3}\right)$, such a particle could serve as an anodic site and dissolve preferentially. Given that such particles are relatively anodic when compared to aluminium, their dissolution shifts the alloy's potential in the cathodic direction, thereby diminishing the intergranular corrosion driving force. According to reference [27], the intergranular corrosion of 6056-T6 starts at pits. From Fig. 3(d) it seems that this is also the case for 2050-T8. 

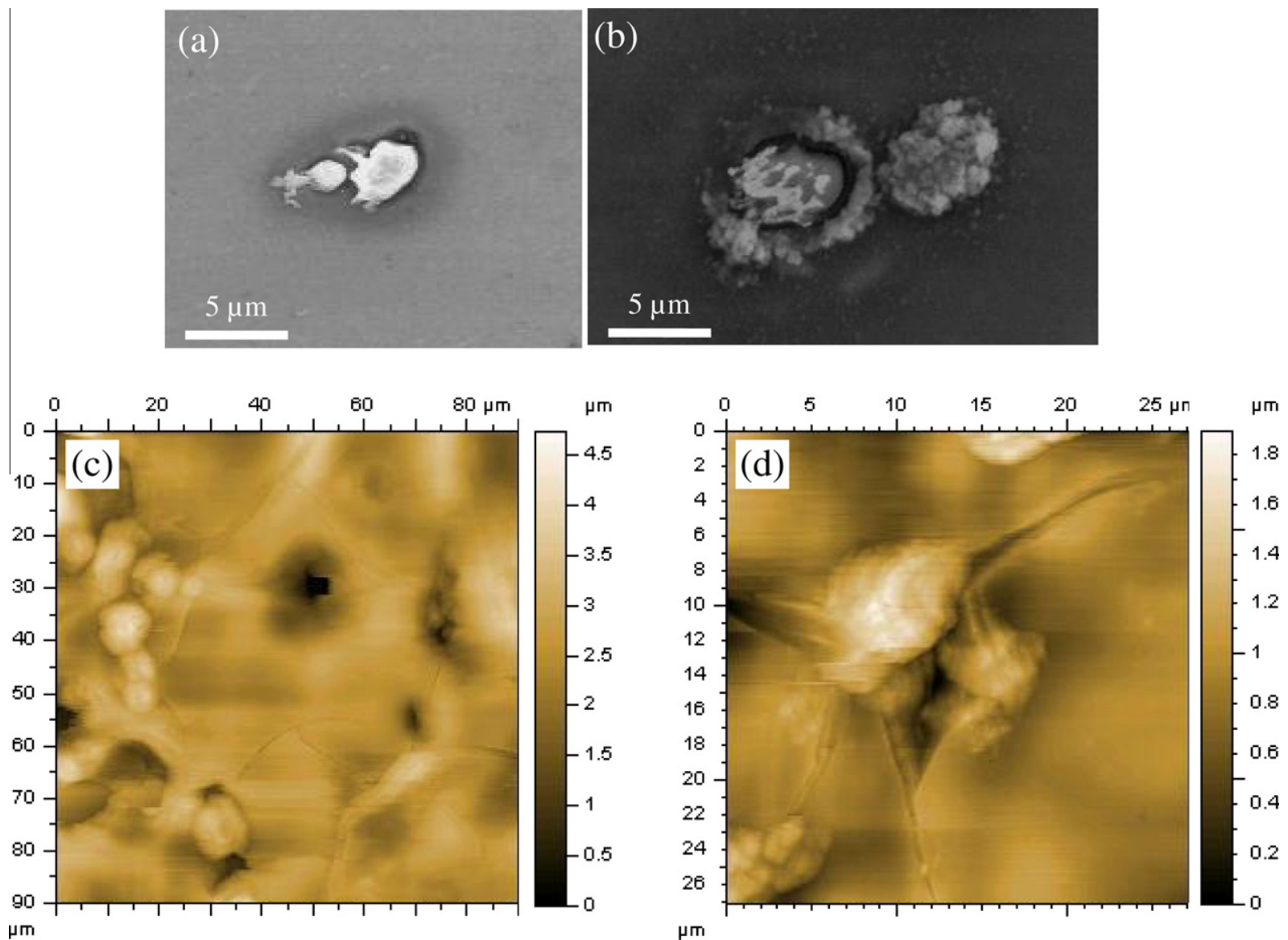

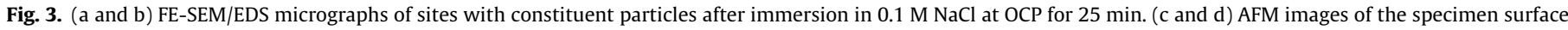
after the corrosion test corresponding to the global polarisation curve shown in Fig. 2(a).

Table 1

Chemical composition of the AA2050-T8 matrix after polishing and after immersion at OCP in $0.1 \mathrm{M} \mathrm{NaCl}$ for $25 \mathrm{~min}$ (at.\%).

\begin{tabular}{|c|c|c|c|c|c|c|}
\hline & 0 & $\mathrm{Al}$ & $\mathrm{Cl}$ & Mn & $\mathrm{Fe}$ & $\mathrm{Cu}$ \\
\hline Matrix after polishing & 0 & 97.93 & 0 & 0 & 0 & 2 \\
\hline Matrix close to constituent particles after immersion at OCP & 8.5 & 88.5 & 0.045 & 0.66 & 0.13 & 2.2 \\
\hline Matrix far from constituent particles after immersion at OCP & 1.7 & 96.4 & 0 & 0.03 & 0 & 1.9 \\
\hline
\end{tabular}

Fig. 4 shows that $E_{\mathrm{b} 2}$ decreases as the specimen surface area in contact with the electrolyte increases. Pitting potential derived from large scale experiments is usually fixed by the corrosion behaviour of the most active particle whereas the pitting potential derived from an experiment on a single particle is usually determined by the weakest zone of the particle.

\subsubsection{Local polarisation curves}

Only the second stage (i.e. potentials above $E_{\mathrm{b} 2}$ ) is visible in the local polarisation curves (Fig. 2(a and b)). A similar result was obtained using three capillary diameters. It has been shown $[24,28]$ that the number of stages in a polarisation curve is related to the surface area of the sample. Only a single stage has been detected for very small surface areas in contact with the electrolyte. It has been suggested that constituent particles do not all react at the same time. As a result of the low number of constituent particles within a small surface area, the anodic current relating to their dissolution is extremely low and the associated stage (i.e. potentials above $\left.E_{\mathrm{b} 1}\right)$ is not visible. Any differences observed between macro- and micro-measurements were therefore associated with the volume fraction of constituent particles in the material.

\subsection{Corrosion behaviour of AA2050-T8 aluminium alloy in $0.1 \mathrm{M} \mathrm{NaCl}$ after LSP}

\subsubsection{Global polarisation curves}

To determine the influence of LSP on the electrochemical behaviour of AA2050-T8, measurements were carried out at sites of the pure matrix that were free of any visible defects. The global polarisation curve in $0.1 \mathrm{M} \mathrm{NaCl}$ is shown in Fig. 5(a). The two stages are observed on this curve. The more active potential $\left(E_{\mathrm{b} 1}\right.$ at approximately $-850 \mathrm{mV}$ vs. $\mathrm{AgCl} / \mathrm{AgCl}$ ) is once again associated with the oxidation of sites containing constituent particles. This was confirmed by surface observations that were made after corrosion tests under potentiostatic control (at $-630 \mathrm{mV}$ vs. $\mathrm{Ag} / \mathrm{AgCl}$, between $E_{\mathrm{b} 1}$ and $E_{\mathrm{b} 2}$ ), as shown in Fig. 6(a and b). The surface morphology obtained was very close to that found in the absence of LSP treatment. For potentials greater than the second breakdown 


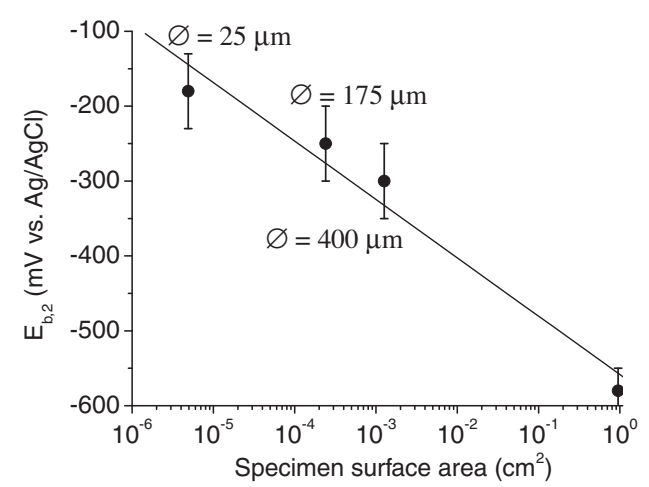

Fig. 4. Evolution of the pitting potential $E_{\mathrm{b} 2}$ of $\mathrm{AA} 2050$-T8 vs. the specimen surface area exposed to the electrolyte. Data obtained both from global and local measurements.
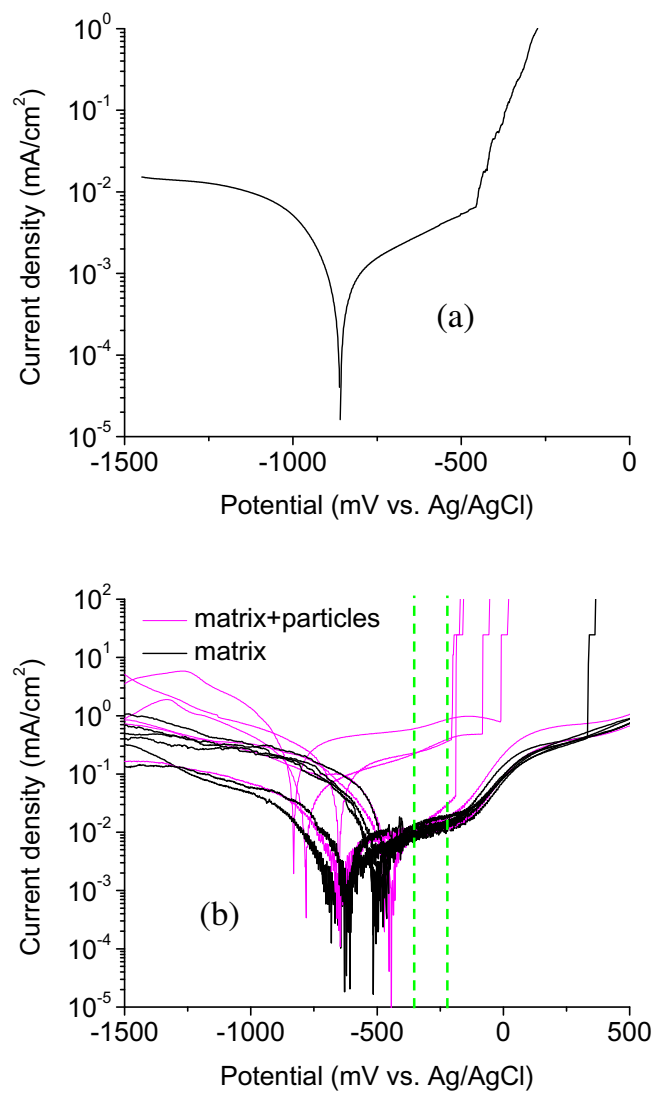

Fig. 5. (a) Global polarisation curve $(16.6 \mathrm{mV} / \mathrm{s})$ for AA2050-T8 aluminium alloy in $0.1 \mathrm{M} \mathrm{NaCl}$ at $25^{\circ} \mathrm{C}$. The experiment was performed on the LSP-treated surface. (b) Local polarisation curves obtained under the same experimental conditions using $25 \mu \mathrm{m}$ diameter capillaries.

potential $\left(E_{\mathrm{b} 2}\right.$ at $-450 \mathrm{mV}$ vs. $\left.\mathrm{Ag} / \mathrm{AgCl}\right)$, numerous pits are observed in grains, as shown in Fig. 6(b). These pits initiated at sites containing constituent particles. In contrast with the previous case, no intergranular corrosion developed in the matrix. Therefore, it can be concluded that LSP treatment has beneficial effects on the corrosion resistance of the matrix.

\subsubsection{Local polarisation curves}

Fig. 5(b) shows the local polarisation curves obtained in $0.1 \mathrm{M}$ $\mathrm{NaCl}$, at sites containing the pure matrix and at those containing the matrix with a cavity. These sites exhibit a large passive range.
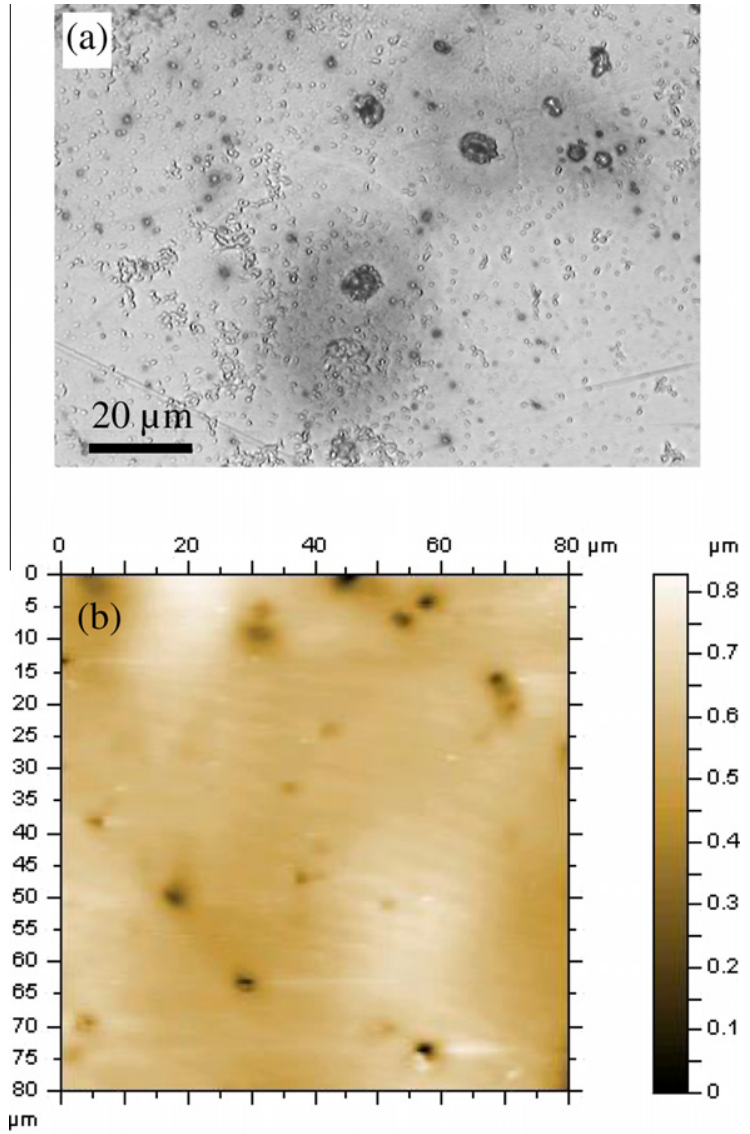

Fig. 6. (a) Optical images of the specimen surface after a potentiostatic test at $-630 \mathrm{mV}$ vs. $\mathrm{Ag} / \mathrm{AgCl}$ for $20 \mathrm{~min}$. (b) AFM image of the specimen surface after the corrosion test corresponding to the global polarisation curve shown in Fig. 5(a).

The current density was low $\left(0.01 \mathrm{~mA} \mathrm{~cm}^{-2}\right.$, as opposed to $0.05-$ $0.1 \mathrm{~mA} \mathrm{~cm}^{-2}$ after polishing), and no pitting potential could be identified. Therefore, LSP has beneficial effects on the electrochemical behaviour and corrosion resistance of the pure matrix. This is mainly attributed to the formation of a surface under compression.

After LSP treatment, scattering was observed in the local polarisation curves of sites containing constituent particles, as shown in Fig. 5(b). The current density was between 0.25 and $0.65 \mathrm{~mA} \mathrm{~cm}^{-2}$ in the anodic domain, and higher than $1 \mathrm{~mA} \mathrm{~cm}^{-2}$ in the cathodic region. Pitting potentials were slightly more anodic than they were after polishing ( $-50 \mathrm{mV}$ vs. $\mathrm{Ag} / \mathrm{AgCl}$, as opposed to $-100 \mathrm{mV}$ vs. $\mathrm{Ag} / \mathrm{AgCl})$. Therefore, LSP has little influence on the behaviour of sites with constituent particles. Microstructural investigations of the surface were performed after the local measurements. However, these investigations were not helpful to interpret which type of corrosion occurs and which type of corrosion process is responsible for the obtained curves. XRD measurements showed that the surface is under compression after LSP treatment. In the future, thermal-mechanical simulation based on the use of the finite element method will be used to predict mechanical effects induced in the material treated by LSP. Surface stresses may play an important role in corrosion processes after LSP. Local polarization curves will be analysed considering these mechanical effects.

\subsection{Corrosion behaviour of AA2050-T8 aluminium alloy in low chloride concentration solution using SVET}

SVET was then used to map the current distribution across the interface between the polished and the LSP-treated surfaces at 

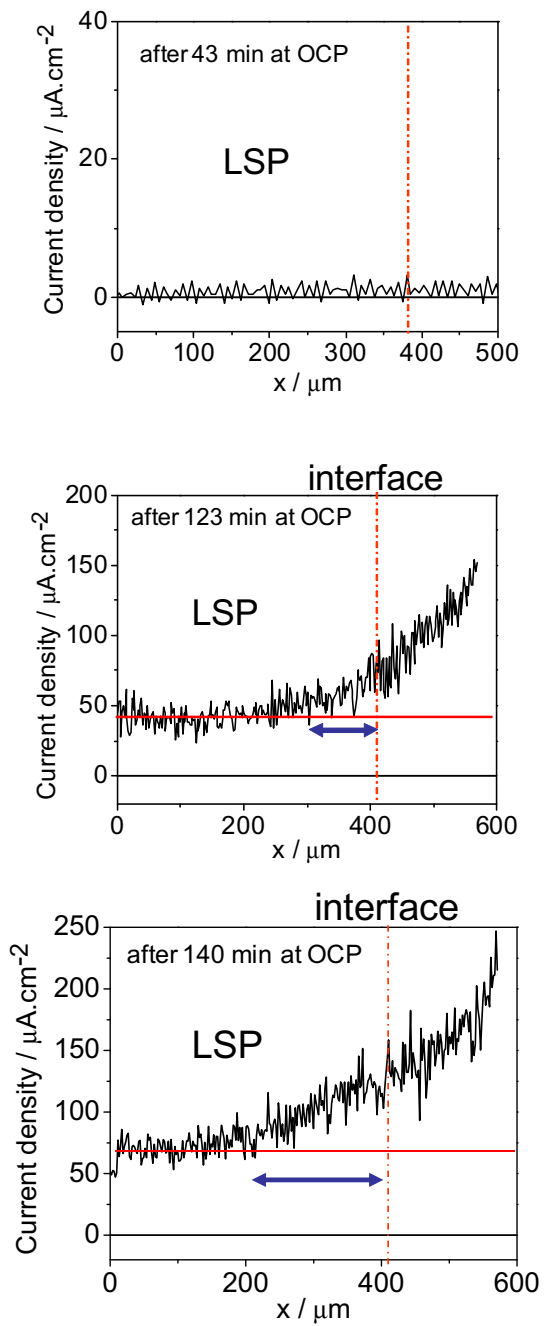
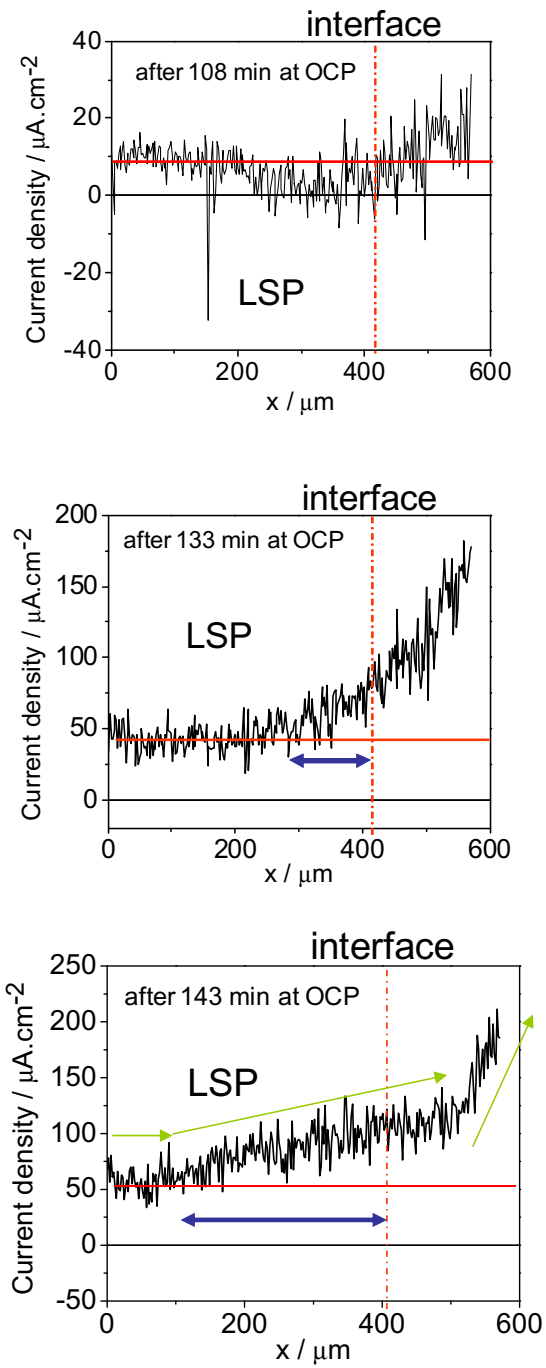

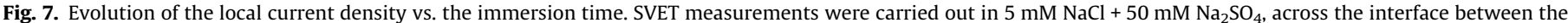
polished and the LSP-treated surfaces.

OCP. A low chloride concentration solution was chosen because SVET measurements are usually performed in low conductivity media to improve the spatial resolution. Conversely, measurements with microcapillaries need high conductivity media due to the very low measured current (small analysed surface area).

The evolution of the normal current density vs. the immersion time is shown in Fig. 7. For $43 \mathrm{~min}$ of immersion, no current was measured. The surface was passive on both sides of the interface. After 108 min of immersion, a current density of $20 \mu \mathrm{A} \mathrm{cm}^{-2}$ was evidenced on the polished surface far from the interface, versus only around $10 \mu \mathrm{A} \mathrm{cm}^{-2}$ on the LSP-treated surface. This indicates that the polished surface is more sensitive to corrosion than the LSP-treated one. It can be mentioned that negative currents were measured at some points on both sides of the interface. As it was discussed in Section 3.1.2, cathodic reactions take place at particles (size in the range of $1-10 \mu \mathrm{m}$ ). The spatial resolution of the SVET does not allow the detection of a current on small particles. Therefore, it was difficult to detect negative currents.

For 123 min of immersion, the current density increased by a factor of 7.5 on the polished surface and only by a factor of 5 on the LSP-treated surface, confirming that the polished surface is more prone to corrosion than the LSP-treated surface. For $123 \mathrm{~min}$ of immersion, the current density remains more-or-less constant on the LSP-treated surface (around $50 \mu \mathrm{A} \mathrm{cm} \mathrm{cm}^{-2}$ ), whereas it increases up to $200 \mu \mathrm{A} \mathrm{cm}^{-2}$ on the polished surface. These results indicate that LSP has beneficial effects on corrosion processes. Indeed, preferential dissolution of the LSP-treated surface near the interface was observed for $123 \mathrm{~min}$ of immersion.

\section{Conclusions}

The corrosion behaviour of AA2050-T8 aluminium alloy was studied after polishing and after laser shock processing (LSP) treatment using the electrochemical microcell technique and the scanning vibrating electrode technique (SVET). The following conclusions can be drawn:

(1) LSP has no influence on the microstructure of AA2050-T8 aluminium alloy. This alloy contains $\mathrm{Al}_{7} \mathrm{Cu}_{2}(\mathrm{Fe}, \mathrm{Mn})$ constituent particles. The main hardening phase was $\mathrm{Al}_{2} \mathrm{CuLi}$.

(2) Extremely low stress values were registered after mechanical polishing. By contrast, the matrix was found to be under compression after LSP.

(3) After polishing, both pitting corrosion at constituent particles and intergranular corrosion were observed. By contrast, no intergranular corrosion developed in the matrix after LSP. 
(4) After LSP, microcell measurements revealed that pitting potential slightly increased (of about $50 \mathrm{mV}$ vs. $\mathrm{Ag} / \mathrm{AgCl}$ ) in sites containing constituent particles. By contrast, the matrix remains always passive. This was attributed to the presence of compressive stresses.

\section{Acknowledgements}

This work was supported by the Agence Nationale de la Recherche (ANR, France) under the project \#BLAN07-2_185038 (CAPSUL) and by CAPES-COFECUB (France, Brazil) under the project \#646/ 2009.

\section{References}

[1] K. Nisancioglu, J. Electrochem. Soc. 137 (1990) 69-77.

[2] E. McCafferty, J. Electrochem. Soc. 150 (2003) B238-B247.

[3] J.L. Searles, P.I. Gouma, R.G. Buchheit, Metall. Mater. Trans. 32A (2001) 28592867.

[4] N. Birbilis, R.G. Buchheit, J. Electrochem. Soc. 152 (2005) B140-B151.

[5] J.O. Park, C.H. Paik, R.C. Alkire, J. Electrochem. Soc. 143 (1996) L174-L176.

[6] A. Davoodi, J. Pan, C. Leygraf, S. Norgren, Appl. Surf. Sci. 252 (2006) 5499-5503.

[7] M.M. Lohrengel, A. Moehring, M. Pilanski, Electrochim. Acta 47 (2001) 137 141

[8] M.M. Lohrengel, A. Moehring, M. Pilanski, Fresenius. J. Anal. Chem. 367 (2000) 334-339.

[9] A.W. Hassel, M.M. Lohrengel, Electrochim. Acta 42 (1997) 3327-3333.
[10] H. Böhni, T. Suter, F. Assi, Surf. Coat. Technol. 130 (2000) 80-86

[11] T. Suter, R.C. Alkire, J. Electrochem. Soc. 148 (2001) B36-B42.

[12] F. Andreatta, M.M. Lohrengel, H. Terryn, J.H.W. de Wit, Electrochim. Acta 48 (2003) 3239-3247.

[13] H. Krawiec, V. Vignal, Z. Szklarz, J. Solid-State Electrochem. 13 (2009) 11811191.

[14] O. Guseva, P. Schmutz, T. Suter, O. von Trzebiatowski, Electrochim. Acta 54 (2009) 4514-4524.

[15] C. Rubio-González, C. Felix-Martinez, G. Gomez-Rosas, J.L. Ocaña, M. Morales, J.A. Porro, Mater. Sci. Eng. A 528 (2011) 914-919.

[16] C. Rodopoulos, C.S. Romero, S.A. Curtis, E. De Los Rios, P. Peyre, J, Mater. Eng. Perform. 12 (2003) 414-419.

[17] T. Suter, E.G. Webb, H. Bohni, R.C. Alkire, J. Electrochem. Soc. 148 (2001) B174B185.

[18] H. Krawiec, V. Vignal, R. Akid, Surf. Interface Anal. 40 (2008) 315-319.

[19] H. Krawiec, V. Vignal, R. Akid, Electrochim. Acta 53 (2008) 5252-5259.

[20] V. Hauk, Structural and Residual Stress Analysis by Nondestructive Methods, Elsevier, Amsterdam, 1997.

[21] H. Krawiec, V. Vignal H. Amar, P. Peyre, Electrochim. Acta in press, doi:10.1016/j.electacta.2011.01.091.

[22] Ph. Lequeu, K.P. Smith, A. Daniélou, J. Mater. Eng. Perform. 19 (2010) 841-847.

[23] S. Maitra, G.C. English, Metall. Trans. 12A (1981) 535-541.

[24] V. Guillaumin, G. Mankowski, Corros. Sci. 41 (1999) 421-438.

[25] L. Lacroix, L. Ressier, C. Blanc, G. Mankowski, J. Electrochem. Soc. 155 (2008) C131-C137.

[26] D.O. Sprowls, R.H. Brown, Stress-corrosion mechanisms for aluminium alloys, Conference Fundamental Aspects of Stress Corrosion Cracking, NACE, Houston (1969) 466-512.

[27] V. Guillaumin, G. Mankowski, Corros. Sci. 42 (2000) 105-125.

[28] C. Augustin, E. Andrieu, C. Blanc, G. Mankowski, J. Delfosse, J. Electrochem. Soc. 154 (2007) C637-C644. 